\title{
INGER DAGMAR YVONNE WIKSTRÖM-HAUGEN (1944-2021), IN MEMORIAM
}

On Friday March 19, 2021, we received the irrevocable message that Inger Wikström has passed away. For me, her death did not come unexpected as she wrote to me a couple of months ago that she suffered from a very serious disease. In a relatively short time, her condition deteriorated, and she was confronted with the fact that this was a struggle she was not going to win. I believe it was a relief for her not to experience any more pain.

Inger Wikström was born in 1944 in Gothenburg and went to school and Univer-

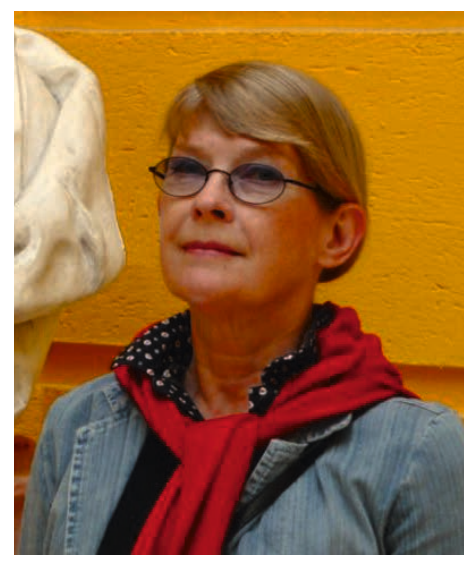
sity there. Upon completion of her studies in 1968, she with great energy and enthusiasm started describing and sorting out the medical collection of the Salgrenska university hospital. This led her to become the director of the then newly founded Museum of Medical History. She held this position until her retirement in 2010.

In October that year, Inger received an honorary doctorate of the Faculty of Humanities of the University of Gothenburg. This was a token of great recognition for her very productive and successful work. Yet another sign of appreciation followed in 2016 as she was awarded with the Cultural Heritage Prize of the Association of Otterhällan.

The main source of our acquaintance was our membership in the European Association for Museums of Medical Sciences (EAMHMS). Inger was a member of the Board from the early beginning in 1983. I followed in 1986 when we met in London at the second Conference. After some years, Inger was chosen to be one of the Vice Presidents of this Association. Her role in the organization of the 8th Conference that was held in Gothenburg was unforgettable. It was astonishing not only to see this great museum, but also the excursions and the 
social programs were fantastic. Because of her many credits in the early 2000's, Inger Wikstrom was awarded with an honorary membership of the Association.

We became more closely connected as Inger showed increasing interest in the biannual workshops that were organized under the auspices of the Association. Participants from several countries all learned a lot from her experience, skills and warm personality. After her retirement, Inger remained an enthusiastic participant in our workshops. These workshops were held in various countries, notably in the East of Europe, the last one in Kiev (Ukraine) in 2017. For the last 10 years, she was accompanied by her almost equally enthusiastic husband, Bertil Haugen.

In conclusion, the Medical History and Museum world shall miss a very dear colleague and friend. As we pay Inger our last respects, we hope she will find rest and peace. Our deepest sympathies and warmest thoughts are with her husband Bertil.

Willem J. Mulder 